\title{
Exertional gastro-oesophageal reflux: a mechanism for symptoms in patients with angina pectoris and normal coronary angiograms
}

\author{
P M SCHOFIELD, D H BENNETT, P J WHORWELL, N H BROOKS, C L BRAY, \\ C WARD, P E JONES
}

\begin{abstract}
During 24 hour oesophageal pH monitoring 52 patients who had angina pectoris and normal coronary angiograms underwent exercise testing, as far as their symptoms allowed, on a treadmill to determine whether gastro-oesophageal reflux occurred during exertion. In 11 patients the 24 hour oesophageal $\mathrm{pH}$ score was abnormally high; 10 of these showed exertional gastrooesophageal reflux, and in nine this was associated with their usual chest pain. A further 13 patients had a normal 24 hour pH score but had exertional reflux coincident with chest pain during exercise testing. The mean lower oesophageal sphincter pressure in both of these groups of patients was appreciably lower than that in 28 patients who had a normal 24 hour $\mathrm{pH}$ score and no exertional reflux.

These findings suggest that exertional gastro-oesophageal reflux accounts for the symptoms of a large proportion of patients who have angina pectoris and normal coronary angiograms and that oesophageal pH monitoring during exercise testing on a treadmill enables this group of patients to be identified.
\end{abstract}

\section{Introduction}

Among patients referred for selective coronary angiography because of chest pain $10 \%$ to $30 \%$ are found to have either normal coronary arteries or only minor narrowing of the coronary lumen.$^{1-3}$ Between $18 \%$ and $76 \%$ of patients who have "angina pectoris and normal coronary angiograms" have oesophageal dysfunction, including abnormal gastro-oesophageal reflux and oesophageal motility disorder..$^{48}$

It is impossible to be certain, however, that the chest pain is due to an oesophageal disorder unless the oesophageal abnormality has been shown to occur simultaneously with the symptoms. Furthermore, many previous studies of oesophageal function in patients who have "angina pectoris and normal coronary angiograms" have included a large proportion of patients who have atypical chest pain $\left(>50 \%\right.$ in the series of Dart $e t a l^{5}$ and de Caestecker $\left.e t a l^{8}\right)$ and patients who had not been shown to have entirely normal coronary angiograms (60\% in the series of Brand $e t a l^{4}$ and $40 \%$ in that of de Caestecker $\left.e t a l^{8}\right)$.

In this study we assessed the intraoesophageal $\mathrm{pH}$, including the response during exercise testing on a treadmill, in 52 patients who had typical angina pectoris and completely normal coronary angiograms.

Wythenshawe Hospital, Manchester

P M SCHOFIELD, MRCP, cardiology research fellow, regional cardiac unit D H BENNETT, MD, FRCP, consultant cardiologist, regional cardiac unit N H BROOKS, MD, MRCP, consultant cardiologist, regional cardiac unit C L BRAY, BSC, FRCP, consultant cardiologist, regional cardiac unit C WARD, MD, FRCP, consultant cardiologist, regional cardiac unit

P E JONES, MD, MRCP, consultant gastroenterologist, department of gastroenterology

Department of Gastroenterology, Withington Hospital, Manchester P J WHORWELL, MD, MRCP, consultant gastroenterologist.

Correspondence to: Dr P M Schofield, Regional Adult Cardiac Unit, Broadgreen Hospital, Liverpool L14 3LB.

\section{Patients and methods}

We studied 52 consecutive patients aged 30-68 (mean 46) ( 31 women, 21 men) who had been referred to the regional cardiac unit at Wythenshawe Hospital over 15 months. All of the patients complained of recurrent exertional chest pain that was typical of angina pectoris in its site, character, and distribution.' Selective coronary angiograms, taken from several projections, were reviewed by at least three experienced observers and confirmed to be completely normal.

Oesophagogastroduodenoscopy was performed in all patients by an experienced endoscopist, and biopsy samples from the lower oesophagus were obtained. The patients also underwent 24 hour monitoring of ambulatory intraoesophageal $\mathrm{pH}$. A glass $\mathrm{pH}$ electrode (Microelectrodes Inc, type MI-506) under fluoroscopic control was positioned $5 \mathrm{~cm}$ above the gastro-oesophageal junction. After the electrode had been calibrated recording was started with an ambulatory $\mathrm{pH}$ recorder unit (Lectromed Ltd, type 5150), and a permanent tracing was obtained with the $\mathrm{pH}$ replay unit (Lectromed Ltd, type 5151). In addition, on a different occasion, all of the patients underwent oesophageal manometry with an Arndorfer hydraulic capillary infusion system linked to a Lectromed multichannel pen recorder. Only the lower oesophageal sphincter pressure measurements are reported here, though the remaining data will be published elsewhere.

Treatment with all drugs was stopped $\mathbf{4 8}$ hours before, and during, these investigations. The patients' activities during $\mathrm{pH}$ monitoring were not restricted except that they were not allowed to eat or drink fruit or fruit based drinks. The patients were provided with a diary card to record the times of any symptoms and of eating, drinking, going to bed, and getting up. An event marker was activated at these times.

During oesophageal $\mathrm{pH}$ monitoring the patients underwent exercise testing, as far as their symptoms allowed, on a treadmill with the standard Bruce protocol to determine whether exertional gastro-oesophageal reflux $(\mathrm{pH}<4)$ occurred. The beginning and end of exercise were recorded with the event marker. The development of at least $1 \mathrm{~mm}$ horizontal or downsloping ST segment depression or at least $2 \mathrm{~mm}$ upsloping ST depression from resting values at 0.08 second after the $\mathrm{J}$ point was considered to be abnormal. ${ }^{10}$

Using six points from the 24 hour oesophageal $\mathrm{pH}$ record we calculated a "score" as described by Johnson and DeMeester. ${ }^{11}$ This was the proportion of time that the oesophageal $\mathrm{pH}$ was less than 4 during the whole recording and also the proportion of time when the patient was in the supine and upright positions, the total number of reflux episodes, the number of episodes of longer than five minutes' duration, and the duration of the longest reflux episode. A score greater than 21.3 was considered to be abnormal. ${ }^{11}$ The number of episodes of chest pain associated with gastrooesophageal reflux and the number not associated with reflux during the 24 hours were also determined.

Statistical analysis examined the group differences with $t$ tests and analysis of variance. Proportions were compared with the $\chi^{2}$ test. When we analysed the number of episodes of chest pain associated and not associated with gastro-oesophageal reflux the data that we used were counts of discrete events; so had a theoretical Poisson distribution. The data were transformed into a normal distribution by adding one to each observation and taking natural logarithms. A series of mathematical models was then fitted to the transformed data to investigate the relation among episodes of chest pain, gastro-oesophageal reflux, and patient group. The variables of each model were estimated by the method of maximum likelihood with the GLIM statistical computer package. ${ }^{12}$ The results obtained from fitting the models were converted into a table of standard analysis of variance.

\section{Results}

Eleven patients had an abnormally high 24 hour oesophageal $\mathrm{pH}$ score $\mathrm{e}^{11}$ (group I). Nine of these showed gastro-oesophageal reflux during exercise testing on the treadmill that was associated with their usual chest pain, one patient had reflux not associated with chest pain, and one patient had chest pain not associated with reflux. A further 13 patients had a normal 24 hour 
pH score but experienced chest pain coincident with gastro-oesophageal reflux during exercise testing (group II). The figure shows two examples.

Twenty eight patients had a normal 24 hour $\mathrm{pH}$ score and did not have gastro-oesophageal reflux during exercise testing (group III) (table I). The 24 patients in groups I and II were considered to have gastro-oesophageal reflux disease. There was no significant difference in age or sex between the patients in groups I and II (mean (SD) age 45.5 (7.9) years, 10 men and 14 women) and the patients in group III (46.5 (8.7) years, 11 men and 17 women).

The mean 24 hour oesophageal $\mathrm{pH}$ score of the patients in group I was greater than that of the patients in group II and of the patients in group III.
TABLE III-Symptoms and ST segment response during exercise testing on treadmill

\begin{tabular}{lcc}
\hline & $\begin{array}{c}\text { Groups I and II } \\
(\mathbf{n}=24)\end{array}$ & $\begin{array}{c}\text { Group III } \\
(\mathbf{n}=28)\end{array}$ \\
\hline ST segment response: & 9 & 14 \\
$\quad$ Abnormal & 15 & 14 \\
$\quad \begin{array}{l}\text { Normal } \\
\text { Chest pain on treadmill: } \\
\text { Yes }\end{array}$ & $23^{\star}$ & 16 \\
No & $1^{\star}$ & 12 \\
\hline Significantly different from group III $(\mathrm{p}<0 \cdot 01)$. & &
\end{tabular}
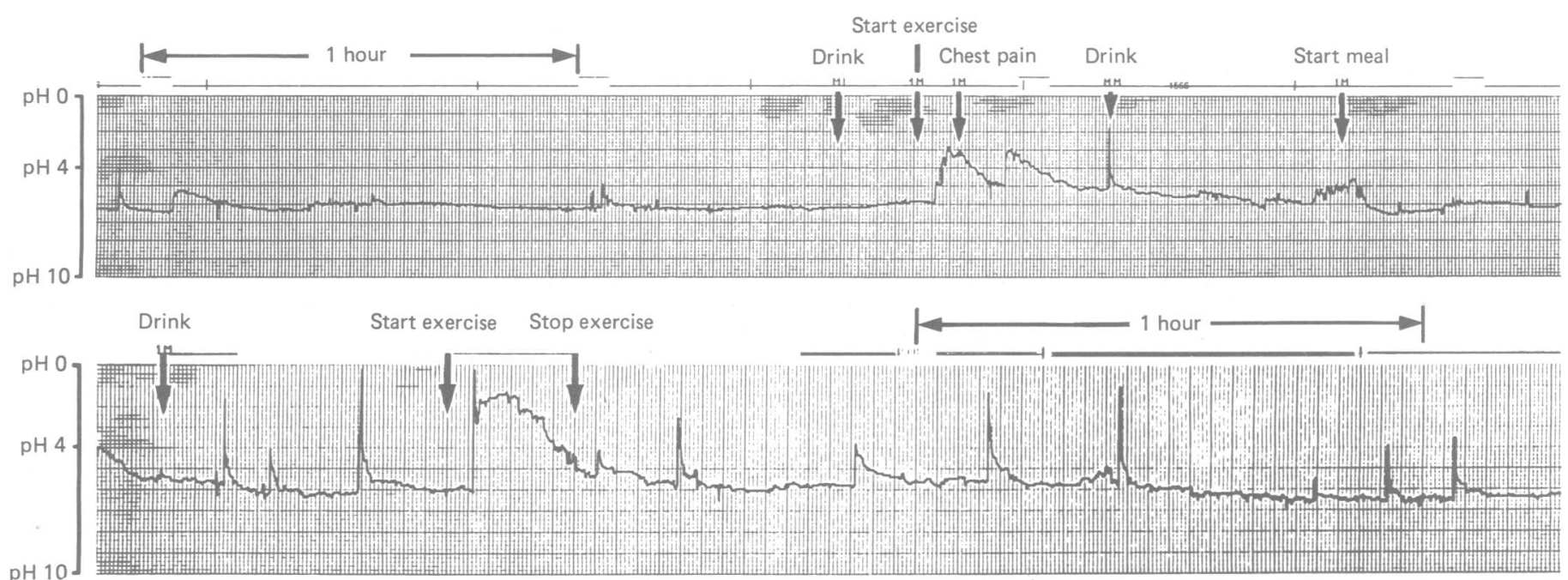

Above: Intraoesophageal $\mathrm{pH}$ recording before, during, and after exercise testing on treadmill (duration 10 minutes) showing gastro-oesophageal reflux ( $\mathrm{pH}<4$ ) during exercise. Event marker $(M)$ was activated on occasions indicated. Below: intra-oesophageal $\mathrm{pH}$ recording showing prolonged episode of gastro-oesophageal reflux ( $\mathrm{pH}<4$ for 10 minutes) during exercise testing on treadmill and several other brief episodes.

TABLE I-Chest pain and gastro-oesophageal reflux during exercise testing on treadmill

\begin{tabular}{lcccc}
\hline & $\begin{array}{c}\text { Group I } \\
(\mathrm{n}=11)\end{array}$ & $\begin{array}{c}\text { Group II } \\
(\mathrm{n}=13)\end{array}$ & $\begin{array}{c}\text { Group III } \\
(\mathrm{n}=28)\end{array}$ & Total \\
\hline No chest pain, no reflux & 0 & 0 & 12 & 12 \\
Chest pain, no reflux & 1 & 0 & 16 & 17 \\
No chest pain, reflux & 1 & 0 & 0 & 1 \\
Chest pain, reflux & 9 & 13 & 0 & 22 \\
\hline
\end{tabular}

The mean scores of the patients in group II and of the patients in group III, however, were similar (table II). The patients in group II therefore showed gastro-oesophageal reflux induced by exercise but did not show appreciable reflux during periods of inactivity. The mean lower oesophageal sphincter pressure of the patients in group III was significantly greater than that of the patients who had gastro-oesophageal reflux disease $(p<0.01)$. There was no significant difference, however, in the lower oesophageal sphincter pressure between the patients in group I and the patients in group II (table II). Macroscopic and microscopic evidence of oesophagitis was found in six patients $(55 \%)$ in group I, five patients (38\%) in group II, and one patient $(4 \%)$ in group III. In addition, one patient in group II and two patients in

TABLE II-Lower oesophageal sphincter pressure and 24 hour pH score. Values are means ( $95 \%$ confidence intervals)

\begin{tabular}{lccc}
\hline & $\begin{array}{c}\text { Group I } \\
(n=11)\end{array}$ & $\begin{array}{c}\text { Group II } \\
(n=13)\end{array}$ & $\begin{array}{c}\text { Group III } \\
(n=28)\end{array}$ \\
\hline 24 Hour oesophageal pH score* & $\begin{array}{c}94 \cdot 2 \\
(53 \cdot 4 \text { to } 135 \cdot 0)\end{array}$ & $\begin{array}{c}12 \cdot 0 \\
(9 \cdot 4 \text { to } 14 \cdot 6)\end{array}$ & $\begin{array}{c}13 \cdot 9 \\
(11 \cdot 4 \text { to } 16 \cdot 4)\end{array}$ \\
$\begin{array}{l}\text { Lower oesophageal sphincter pressure } \\
(\mathrm{mm} \mathrm{Hg})\end{array}$ & $\begin{array}{c}14 \cdot 3 \\
(11.0 \text { to } 17 \cdot 6)\end{array}$ & $\begin{array}{c}11 \cdot 2 \\
(9 \cdot 2 \text { to } 13 \cdot 2)\end{array}$ & $\begin{array}{c}21 \cdot 8+ \\
(19 \cdot 5 \text { to } 24 \cdot 1)\end{array}$ \\
\hline
\end{tabular}

* Upper limit of normal $=21 \cdot 3$.

† Significantly different from group I and group II ( $<<0 \cdot 01)$. group III had microscopic evidence of oesophagitis but not macroscopic evidence.

During exercise testing on the treadmill nine patients (38\%) (four men, five women) from groups I and II showed an abnormal ST segment response compared with 14 patients ( $50 \%$ ) (six men, eight women) from group III; the difference was not significant (table III). Twenty three patients $(96 \%)$ from groups I and II, however, experienced their usual chest pain during exercise testing compared with only 16 patients $(57 \%)$ from group III $\left(\chi^{2}=10 \cdot 3\right.$, $\mathrm{df}=1, \mathrm{p}<0.01)$ (table III).

TABLE IV-Symptoms during 24 hour oesophageal pH monitoring. Values are means (95\% confidence intervals)

\begin{tabular}{|c|c|c|c|}
\hline & $\underset{(n=11)}{\text { Group I }}$ & $\underset{(n=13)}{\text { Group II }}$ & $\underset{(n=28)}{\text { Group III }}$ \\
\hline Total No of episodes of chest pain & $\begin{array}{c}3 \cdot 00^{\star} \\
(2 \cdot 13 \text { to } 4 \cdot 10)\end{array}$ & $\begin{array}{c}3 \cdot 12^{\star} \\
(2 \cdot 43 \text { to } 3 \cdot 94)\end{array}$ & $\begin{array}{c}1.34^{\star} \\
(0.88 \text { to } 1.92)\end{array}$ \\
\hline $\begin{array}{l}\text { Associated with gastro-oesophageal } \\
\text { reflux }\end{array}$ & $\begin{array}{c}2.54 \\
(1.76 \text { to } 3 \cdot 56)\end{array}$ & $\begin{array}{c}2 \cdot 30 \\
(1 \cdot 75 \text { to } 2 \cdot 97)\end{array}$ & $\begin{array}{c}0.15 \\
(0 \text { to } 0.32)\end{array}$ \\
\hline $\begin{array}{l}\text { Not associated with gastro- } \\
\text { oesophageal reflux }\end{array}$ & $\begin{array}{c}0.37 \\
(0 \cdot 10 \text { to } 0 \cdot 70)\end{array}$ & $\begin{array}{c}0.68 \\
(0.31 \text { to } 1 \cdot 17)\end{array}$ & $\begin{array}{c}1.17 \\
(0.76 \text { to } 1.68)\end{array}$ \\
\hline
\end{tabular}

$\star$ Geometric mean.

The number of episodes of chest pain associated with gastro-oesophageal reflux experienced by the patients in group I and group II was significantly greater than the number not associated with reflux $(p<0.01)$ (table IV). By contrast, chest pain associated with reflux occurred only occasionally in the patients in group III, and the number of episodes was significantly lower than the number not associated with reflux $(p<0.01)$. In addition, the total number of episodes of chest pain during oesophageal $\mathrm{pH}$ monitoring experienced by group III was significantly lower than the total number experienced by both group I and group II $(p<0 \cdot 01$ ) (table IV). Several brief 
episodes of gastro-oesophageal reflux that were not associated with any symptoms occurred in patients from each of the three groups.

\section{Discussion}

Patients who have angina pectoris and normal coronary angiograms are a common clinical problem. ${ }^{1-3}$ There have been several studies examining oesophageal motility in patients who have chest pain unconnected with the heart, ${ }^{43-16}$ but to our knowledge only two of them monitored distal oesophageal $\mathrm{pH} .{ }^{68}$ Though oesophageal abnormalities have been shown in many of these patients, it has proved difficult to establish a temporal relation between the symptoms and the abnormality. ${ }^{4}$ The use of intravenous edrophonium has been proposed as the most useful and safest technique for inducing the simultaneous occurrence of symptoms and oesophageal dysmotility. ${ }^{17} 18$

DeMeester et al showed abnormal gastro-oesophageal reflux during 24 hour $\mathrm{pH}$ monitoring in $23(46 \%)$ of 50 patients who had angina pectoris and normal coronary angiograms. ${ }^{6}$ de Caestecker $e t$ al found abnormal reflux in $14(47 \%)$ of 30 patients who had "unexplained chest pain," but fewer than $60 \%$ of their patients had normal coronary angiograms and more than $50 \%$ had atypical chest pain. ${ }^{8}$ All of the patients in our series had entirely normal coronary angiograms and described typical angina pectoris. Eleven patients (21\%) were found to have abnormal gastro-oesophageal reflux during 24 hour monitoring, and 10 of these showed gastrooesophageal reflux during exercise testing on the treadmill. A further 13 patients who had a normal 24 hour $\mathrm{pH}$ score showed exertional reflux associated with chest pain during exercise testing. Thus of 23 patients (44\%) in this series who had reflux on exertion, 22 had the condition simultaneously with chest pain. The occurrence of gastro-oesophageal reflux during exercise testing has not been assessed previously in a large group of patients, though it was shown in three of eight patients reported by DeMeester et al. ${ }^{6}$ Thorpe also showed exertional gastro-oesophageal reflux in three of nine patients who had angina and normal coronary arteriograms. ${ }^{19}$

Of the 23 patients found to have abnormal gastro-oesophageal reflux by DeMeester et al, ${ }^{6}$ only 13 experienced chest pain during the study, and in 12 this was associated with an episode of reflux. Our results suggest that exercise testing on the treadmill is a useful "stress test" for gastro-oesophageal reflux, as $91 \%$ of our patients who had an abnormal 24 hour $\mathrm{pH}$ score showed reflux during exercise testing. In addition to these patients, who had gastrooesophageal reflux during exercise and rest, there was a further group of patients in whom reflux was induced by exercise, though reflux tended not to occur during periods of inactivity. We found that in both groups of patients the mean resting lower oesophageal sphincter pressure was less than that in patients who did not have gastro-oesophageal reflux disease.

Electrocardiographic changes and angina pectoris have been shown when acid is instilled into the oesophagus. ${ }^{2021}$ We found an abnormal ST segment response to exercise in $38 \%$ of the patients who had gastro-oesophageal reflux disease and in half of those who did not have reflux. The recent finding of Davies et al that oesophageal stimulation reduces the exertional angina threshold in patients who have coronary artery disease ${ }^{22}$ underlines the close relation between the heart and the oesophagus and may be relevant to patients who have mild coronary artery disease $(<30 \%$ reduction of intraluminal diameter) ${ }^{23}$ many of whom have been included in previous studies of chest pain unconnected with the heart. ${ }^{82}$ Sixteen of the 28 patients in the present study who did not have gastro-oesophageal reflux disease experienced chest pain during treadmill testing. The cause of their symptoms may be left ventricular dysfunction, which has been shown in patients who have angina pectoris and normal coronary arteries. ${ }^{24}$

The results of this study suggest that oesophageal $\mathrm{pH}$ monitoring during exercise testing on the treadmill should be performed in patients who have angina pectoris and normal coronary angiograms. This procedure identifies patients who have gastro-oesophageal reflux on exertion coincident with chest pain but have otherwise normal results of oesophageal $\mathrm{pH}$ studies, and it also may confirm the association between symptoms and reflux in patients who have abnormal results of $\mathrm{pH}$ studies. Oesophageal $\mathrm{pH}$ monitoring during exercise testing identified 23 of the 24 patients in this study who had angina pectoris related to gastro-oesophageal reflux disease, suggesting that 24 hour monitoring may not be necessary when investigating such patients. DeMeester et al showed that patients who had chest pain coincident with reflux responded positively to antireflux treatment, both medical and surgical. ${ }^{6}$ The response to treatment of patients in the present study, however, has not yet been determined.

We thank Mrs M Rooney for preparing the manuscript and Mrs J Clarke, Miss R Dodd, and Mrs D Massey for their help with the oesophageal investigations. This work is part of a study which will be submitted by PMS to the University of Manchester for the MD degree.

\section{References}

1 Proudfit WL, Shirey EK, Sones FM Selective cine coronary arteriography: correlation with clinical findings in 1,000 patients. Circulation 1966;33:901-10.

2 Kemp HG, Vokonas PS, Cohn PF, Gorlin R. The anginal syndrome associated with normal coronary arteriograms: report of a six year experieñce. $A m \mathcal{F}$ Med 1973;54:735-42.

3 Marcandise B, Bourassa MG, Chaitman BR, Lesperance J. Angiographic evaluation of the natural history of normal coronary arteries and mild coronary atherosclerosis. Am $\mathcal{f}$ Cardiol 1978;41:216-20.

4 Brand DC, Martin D, Pope CE. Esophageal manometries in patients with angina-like chest pain Dig Dis $S c i$ 1977;22:300-4.

5 Dart AM, Alban Davies H, Dalal J, Ruttley M, Henderson AH. "Angina" and normal coronary arteriograms: a follow-up study. Eur Heart f 1980;1:97-100.

6 DeMeester TR, O'Sullivan GC, Bermudez G, Midell AI, Cimochowski GE, O'Drobinak J. Esophageal function in patients with angina-type chest pain and normal coronary angiograms. Ann Surg 1982;196:488-98.

7 Blackwell JN, Castell DO. Oesophageal chest pain: a point of view. Gut 1984;25:1-6.

8 de Caestecker JS, Blackwell JN, Brown J, Heading RC. The oesophagus as a cause of recurrent chest pain: which patients should be investigated and which tests should be used? Lancet chest pain: which
1985;ii:1143-6.

9 Master AM. The spectrum of anginal and non-cardiac chest pain. JAMA 1964;187:894-9.

10 Meller J, Goldsmith SJ, Rudin A, et al. Spectrum of exercise thallium-201 myocardial perfusion imaging in patients with chest pain and normal coronary angiograms. Am $\mathcal{F}$ Cardiol 1979;43: 717-23.

11 Johnson LF, DeMeester TR. Twenty-four-hour $\mathrm{pH}$ monitoring of the distal esophagus. A quantitative measure of gastroesophageal reflux. Am $\mathcal{F}$ Gastroenterol 1974;62:325-32.

12 Baker RJ, Nelder JA. The GLIM system. Release 3. Oxford: Numerical Algorithms Group, 1978.

13 Svensson O, Stenport G, Tibbling L, Wranne B. Oesophageal function and coronary angiogram in patients with disabling chest pain. Acta Med Scand 1978;204:173-8.

14 Ferguson SC, Hodges K, Hersh T, Jinich H. Esophageal manometry in patients with chest pain and normal coronary arteriogram. Am $\mathcal{f}$ Gastroenterol 1981;75:124-7.

$15 \mathrm{Kline} M$, Chesne R, Sturdevant RA, McCallum RW. Esophageal disease in patients with anginalike chest pain. Am $\mathcal{f}$ Gastroenterol 1981;75:116-23.

16 Patterson DR. Diffuse oesophageal spasm in patients with undiagnosed chest pain. $f \mathrm{Clin}$ Gastroenterol 1982;4:415-7.

17 Benjamin SB, Richter JE, Cordova CM, Knuff TE, Castell DO. Prospective manometric evaluation with pharmacologic provocation of patients with suspected esophageal motility dysfunction. Gastroenterology 1983;84:893-901.

18 Wu WC, Hackshaw BT, Richter JE, Castell DO. Esophageal manometry with provocation testing in patients with non-cardiac chest pain. Gastroenterology 1984;86:1303.

19 Thorpe A. Importance of oesophageal-function tests in patients with angina-like chest pain. Cardiology in Practice 1984;2:35-8.

20 Serebro HA. The prognostic significance of the viscerocardiac reflex phenomenon. $S$ Afr Med $\mathcal{F}$ 1976;50:769-72.

21 Mellow MH, Simpson AG, Watt L, Schoolmeester L, Haye OL. Esophageal acid perfusion in coronary artery disease. Induction of myocardial ischemia. Gastroenterology 1983;85:306-12.

22 Davies HA, Rush EM, Lewis MJ, Page Z, Brown AL, Petch MC. Oesophageal stimulation lowers exertional angina threshold. Lancet 1985; i:1011-4.

23 Pasternak RC, Thibault GE, Savoia M, DeSanctis RW, Hutter AM. Chest pain with angiographically insignificant coronary arterial obstruction. Clinical presentation and long-term follow-up. Am J Med 1980;68:813-7.

24 Schofield PM, Brooks N, Bennett DH. Left ventricular dysfunction in patients with angina pectoris and normal coronary angiograms. Br Heart $\mathcal{J}$ 1986;56:327-33.

(Accepted 2 April 1987) 